\title{
Opportunistic and Deliberate Disinflation Under Imperfect Credibility
}

\author{
Antulio N. Bomfim and Glenn D. Rudebusch* \\ December 1997
}

\begin{abstract}
One strategy for disinflation prescribes a deliberate path towards low inflation. A contrasting opportunistic approach eschews deliberate action and instead waits for unforeseen shocks to reduce inflation. This paper compares the ability of these two approaches to achieve disinflation-and at what cost. We analyze these issues using the Federal Reserve' s FRB/US model, which allows alternative assumptions to be made about expectations held by agents in the economy; hence, the credibility of the central bank can be considered in assessing the cost of deliberate and opportunistic disinflations.
\end{abstract}

\section{JEL Classification: E52}

Keywords: monetary policy, inflation expectations, policy rules, inflation targets

${ }^{*}$ Federal Reserve Board and Federal Reserve Bank of San Francisco, respectively. We thank Steve Sumner for excellent research assistance. Helpful comments were provided by seminar participants at the 1997 NBER Summer Institute, the IIES, and the Swedish Riksbank, as well as by our many colleagues in the Federal Reserve System. The opinions expressed in this paper are not necessarily shared by anyone else in the Federal Reserve System. 


\section{Introduction}

Central banks in different countries have adopted different strategies for achieving price stability. One approach is to take a deliberate path to an ultimate goal of low inflation. In the past decade, this approach has often been followed using explicit inflation targets (Leiderman and Svensson 1995 and Haldane 1995). For example, in early 1990, New Zealand's central bank announced interim inflation target ranges of 3 to 5 percent by the end of 1990 and 1.5 to 3.5 percent by the end of 1991, as well as an ultimate inflation target range of 0 to 2 percent by the end of 1992. Similarly, in February 1991, with Canadian core inflation of about 4 percent, the Bank of Canada (1991) announced a deliberate disinflation with a target of 3 percent by the end of 1992 and an ultimate target of 2 percent by the end of 1995.

In contrast to a deliberate approach, an opportunistic strategy for disinflation has recently gathered attention. ${ }^{1}$ An opportunistic disinflation policy also assumes an ultimate target of low inflation; however, except when inflation is too high, the opportunistic policymaker's interim inflation target is simply the current rate of inflation. Thus, the opportunistic strategy typically eschews deliberate action to reduce inflation, and instead waits for unforeseen shocks to reduce inflation. An opportunistic strategy for disinflation was described by a participant at the FOMC meeting in December 1989: "Now, sooner or later, we will have a recession. I don't think anybody around the table wants a recession or is seeking one, but sooner or later we will have one. If in that recession we took advantage of the anti-inflation [impetus] and we got inflation down from 4-1/2 percent to 3 percent, and then in the next expansion we were able to keep inflation from accelerating, sooner or later there will be another recession out there. And so, . . . we could

\footnotetext{
${ }^{1}$ For example, see Orphanides and Wilcox (1996), Rudebusch (1996), Meyer (1997), and Orphanides et al. (1997). Like our paper, the last of these studies also investigates opportunism with simulations of an econometric model with explicit expectations. However, the authors do not consider credibility and use a definition of opportunism that is akin to "inflation zone targeting."
} 
bring inflation down from cycle to cycle . . . ." Indeed, the gradual ratcheting down of inflation over time is the hallmark of the opportunistic approach. As long as inflation is not too high, the opportunistic policymaker takes no deliberate action to reduce inflation further, but waits to exploit recessions and favorable supply shocks to lower inflation. When inflation gets pushed down by a shock, the interim inflation target is re-set to equal the new prevailing lower rate, and, in this fashion, price stability is eventually achieved.

How should a policymaker choose, on economic terms, between deliberate and opportunistic strategies for disinflation? Two key concerns are the timing and the cost of the disinflation. An opportunistic approach, which waits for shocks, will almost certainly take longer to reach price stability than a deliberate approach. However, an opportunistic strategy may be able to achieve disinflation at a lower cost, for example, by taking advantage of unforeseen negative price shocks rather than having to create excess slack in the economy. The answer to the choice between these two approaches to disinflation depends, in part, on the nature and the frequency of the shocks that affect the economy.

The costs of a disinflation are also commonly believed to depend on the credibility of the central bank's commitment to the new lower inflation target. Indeed, a major impetus behind the historical adoption of deliberate disinflation policies with explicit inflation targets was the view that by clearly communicating a low inflation goal to the public and by taking transparent actions to achieve that goal, the costs of disinflation could be lowered. As noted in the press release by the Bank of Canada (1991) at the initial announcement of its inflation targets: "The intention in setting out explicit targets . . . is to encourage Canadians to base their economic decisions on this downward path for inflation so that the lower inflation will be more readily achieved. . . " That is, if people believe that inflation will indeed fall, then inflation may be reduced with a smaller cost in terms of lost output and employment. In contrast, during an opportunistic disinflation, a lack of credibility may be a concern. The continued use of the current inflation rate 
as an interim target may foster questions about the importance of the professed ultimate target of low inflation. Also, the future path of the interim inflation target depends to a very large extent on the size and distribution of future shocks to the economy. Thus, the absence of transparent announcements and decisive action under opportunism could well reduce credibility and undermine disinflationary expectations.

In this paper, we shall explore these issues. In the next section, we describe two simple policy rules that capture the essence of the deliberate and opportunistic approaches to disinflation. In section 3, we define credibility and describe how credibility can be gained and lost over time. Section 4 outlines the empirical macroeconomic model of the U.S. economy that we use-the Federal Reserve's FRB/US model. Our discussion of this model focuses on its expectational structure and on the costs of disinflation. Section 5 presents our simulation results, and section 6 concludes.

\section{Alternative Approaches to Disinflation}

This section defines deliberate and opportunistic approaches to disinflation. For both approaches, the impetus for the disinflation comes from a reduction in the ultimate inflation target, $\pi_{t}^{* *}$. After adoption of a new lower ultimate inflation target, the deliberate policymaker immediately begins to take consistent actions to reach that goal. We model this behavior by assuming that the deliberate policymaker follows a simple variant of the Taylor (1993) rule:

$$
i_{t}=r^{*}+\bar{\pi}_{t}+\beta_{1}\left(\bar{\pi}_{t}-\pi_{t}^{* *}\right)+\beta_{2} y_{t}
$$

where $i_{t}$ is the nominal short-term policy interest rate (the federal funds rate), $r^{*}$ is the equilibrium real short-term rate (which is assumed to be known), $\bar{\pi}_{t}$ is 
the 4-quarter inflation rate, and $y_{t}$ is the real output gap. ${ }^{2}$ That is, the deliberate policymaker consistently strives to eliminate inflation deviations from the ultimate target.

The opportunistic policymaker behaves somewhat differently. We assume that the opportunistic policymaker sets the short-term interest rate according to:

$$
i_{t}=r^{*}+\bar{\pi}_{t}+\beta_{1}\left(\bar{\pi}_{t}-\pi_{t}^{*}\right)+\beta_{2} y_{t}
$$

Equation (2) is identical to (1) in all respects, except that the ultimate inflation target does not explicitly appear on its right-hand side. Instead, the opportunistic policymaker sets the short rate according to the gap between current inflation and an interim inflation target, $\pi_{t}^{*}$. To capture the essence of the opportunistic approach to disinflation, we assume that the interim target evolves according to:

$$
\pi_{t}^{*}=\min \left(\pi_{t-1}^{*}, \bar{\pi}_{t-1}\right)
$$

with $\pi_{t}^{*}$ bounded from below by $\pi_{t}^{* *}$.

Equations (2) and (3) imply that as long as inflation is stable $\left(\bar{\pi}_{t}=\bar{\pi}_{t-1}\right)$, the opportunistic policymaker takes no action to reduce it. However, the opportunistic policymaker will attempt to prevent prices from accelerating further. Also, if actual inflation happens to fall below the interim target-because of an unanticipated recession or favorable supply shock-then the opportunistic policymaker resets the interim target to the newly achieved lower inflation. This process continues until the disinflation is achieved and the interim and ultimate targets are equal.

\footnotetext{
${ }^{2}$ Of course, there are many possible rules that could be consistent with a deliberate approach to disinflation, see, for example, Rudebusch and Svensson (1997).
} 


\section{Monetary Policy Credibility}

In the previous section, we introduced the interim and ultimate inflation targets in the rules for monetary policy. Here, we define monetary policy credibility through the relationship between the ultimate inflation target and inflation expectations. We also consider the achievement and the maintenance of credibility.

Our definition of central bank credibility is straightforward. At the beginning of each period, the central bank announces an ultimate inflation target. The private sector must evaluate the future reliability of this target. Agents must judge the central bank's credibility of intent - that is, whether the target represents the true goal of the central bank-and its credibility of action - that is, whether the central bank has the ability to meet the target even if it wants to (say, in the face of fiscal constraints). We measure overall credibility by the extent to which the pronouncement of a target is believed by the private sector in the formation of their long-run inflation expectations. ${ }^{3}$

Specifically, we assume that long-run inflation expectations at time $t$, denoted $\pi_{\infty \mid t}^{e}$, are a weighted average of the current target and last period's (four-quarter) inflation rate:

$$
\pi_{\infty \mid t}^{e}=\lambda_{t} \pi_{t}^{* *}+\left(1-\lambda_{t}\right) \bar{\pi}_{t-1}
$$

The parameter $\lambda_{t}$ (with $1 \geq \lambda_{t} \geq 0$ ) indexes the credibility of the central bank. If $\lambda_{t}=1$, there is perfect credibility, and private sector's long-run inflation expectations are equal to the announced long-run goal of the policymaker. If $\lambda_{t}=0$, there is no credibility, and the inflation target is ignored in the formation of expectations. Intermediate values of $\lambda_{t}$ represent the partial credibility of the announced

\footnotetext{
${ }^{3}$ This definition of credibility differs from much of the theoretical literature, which stresses incentive compatibility in a game-theoretic setting. In an empirical context, we focus on the outcome of such compatibility as the alignment of expectations and targets. Our measure of credibility is precisely the one employed by King (1995) who analyzes the difference between long-run inflation expectations (derived from nominal and real yield curves) and inflation targets. It is also close to the expectational definitions in Johnson (1997a, 1997b) and Croushore and Koot (1994), which employ short-run inflation expectations from surveys.
} 
inflation target. With representative agents, $\lambda_{t}$ may represent the subjective probability that an agent attaches to the future achievement of the target. With heterogeneous agents, $\lambda_{t}$ could be considered the fraction of the population that believes the target will be achieved.

Credibility as indexed by $\lambda_{t}$ is unlikely to be exogenous. The weight that agents place on the announced target plausibly reacts to developments in the economy. For example, targets that are egregiously missed on a consistent basis are likely to be down-weighted in the formation of expectations. There are many possible channels through which economic developments could affect the evolution of credibility. We consider three different mechanisms for endogenous credibility.

In our first mechanism, credibility is established by outcome. If past inflation matches the inflation target, then the target is given more weight by the private sector in the formation of expectations of future inflation. In this formulation, credibility evolves according to

$$
\lambda_{t}=1-\alpha\left|\bar{\pi}_{t-1}-\pi_{t}^{* *}\right| .
$$

That is, credibility is reduced in a linear fashion as (the absolute value of) the deviation of past inflation from the target increases (with the bound $\lambda_{t} \geq 0$ ).

Our second mechanism allows credibility to be established by the behavior of the central bank. Here agents are more forward-looking than in the first formulation. Agents do not just consider inflation over the immediate past, but they assess the stance of monetary policy and forecast inflation one year ahead $\left(\pi_{t+4 \mid t-1}^{e}\right)$. As the near-term forecast for inflation is closer to the target, then, irrespective of past inflation, credibility is higher. Specifically, our formulation is

$$
\lambda_{t}=1-\alpha\left|\pi_{t+4 \mid t-1}^{e}-\pi_{t}^{* *}\right| .
$$

Thus, if the central bank can take actions that can focus near-term inflation expectations on its goal, its long-run credibility will increase even though past inflation 
has not matched the target.

It should be noted that these mechanisms for the establishment of credibility by outcome and by behavior are broadly similar to those used in the theoretical literature on acquiring credibility (or reputation) in repeated games (as surveyed in Rogoff 1989 and Blackburn and Christensen 1989). However, that literature has typically employed "trigger" mechanisms that assumed a quick and complete collapse of credibility after even a minor failure by the policymaker to meet the target. Equations (5) and (6), while in the same spirit, can display more plausible macrodynamics because variation in $\alpha$ allows more flexibility in modeling how much and how quickly agents revise their inflation expectations in response to missed targets. ${ }^{4}$

Finally, in our third channel, credibility may be enhanced merely by the announcement of transparent goals for inflation. In forming long-run inflation expectations, the public may place a higher weight on inflation targets that are clearly and unambiguously stated. Indeed, as noted in the introduction, the recent adoption of deliberate disinflation paths with explicit inflation targets by various central banks was motivated in part by the belief that some credibility could be established by announcement. Such a perspective is not that surprising at central banks where policymakers that are less than circumspect often find that their offthe-cuff comments can move financial markets (and sometimes there is intended "jaw-boning" as well). Still, there is much to be skeptical about regarding credibility by announcement. Presumably, agents do not just listen to policymakers' words but also judge their underlying preferences and incentives. Targets are easy to announce but may be hard to deliver. The empirical evidence on credibility by announcement is decidedly mixed, but there is some evidence that past policy announcements of deliberate disinflations had some small effect on inflation

\footnotetext{
${ }^{4}$ While we view our mechanisms for endogenous credibility as plausible, there are other candidates in the empirical literature. For example, Fuhrer and Hooker (1993) and Huh and Lansing (1997) consider a Bayesian learning mechanism that is perhaps more rigorous in formulation, but would be difficult to implement with our nonlinear policy rule.
} 
expectations (e.g., Johnson 1997a, 1997b and Amano, et al. 1997). We shall consider this possibility in some of our simulations by slightly boosting credibility immediately after the announcement of a deliberate disinflation slightly above what a forward-looking specification would suggest.

\section{The Model}

The FRB/US model that we employ in our analysis is a large-scale macroeconometric model of the U.S. economy with an explicit expectational structure, which was developed at the Federal Reserve Board for analysis and forecasting. Its longrun structure is akin to a neoclassical growth model. In the long run, economic growth is solely a function of population and technology growth, and inflation is determined by the long-run inflation target implicit in the specification of monetary policy. In the short run, however, because of adjustment costs and other dynamic frictions, households and firms are often away from their long-run equilibrium paths, and monetary policy can have significant short-run effects on real activity. Below, we highlight two aspects of the specification that are most relevant for our analysis: the costs of adjustment and the formation of expectations. ${ }^{5}$

\subsection{Evolution of Key Macro Variables}

Two distinct modeling approaches were used in the construction of FRB/US. Nonfinancial variables are assumed to evolve according to a generalized adjustment cost framework. Financial markets are governed by standard arbitrage equilibrium conditions.

Non-Financial Markets. Firms set prices and make factor allocation decisions un-

\footnotetext{
${ }^{5}$ See Bomfim, Tetlow, von zur Muehlen and Williams (1997), Brayton and Tinsley (1996), and Brayton, Mauskopf, Reifschneider, Tinsley and Williams (1997) for more detailed descriptions of the FRB/US model.
} 
der imperfect competition. Households make consumption decisions in the context of a life-cycle framework. We shall use the firms' price setting problem to illustrate the general modeling approach used in all key non-financial equations of FRB/US. ${ }^{6}$ In doing so we shall pay special attention to the role played by expectations in the model's dynamics.

Non-financial variables are modeled according to two basic tenets. First, all economic agents are assumed to be forward looking, with their expectations of future conditions explicitly modeled in all key behavioral equations. Second, decision making in all non-financial markets is subject to non-trivial adjustment costs or frictions that prevent agents from instantaneous reaching their long-run or "target" factor allocations and prices. In practice, this approach is implemented by assuming that agents follow a two-state decision making process. In the first stage, target values for all decision variables are determined; these are the values that would prevail in the absence of adjustment costs. For instance, given imperfect competition and a Cobb-Douglas production function, target prices $\left(p_{t}^{*}\right)$ are a function of marginal costs of production $\left(c_{t}\right)$ and a cyclical mark-up. In the second stage of the decision making process, agents seek to close the gap between actual and target values of their decision variables subject to adjustment costs. Again using price setting as an illustration, the second-stage decision problem reduces to solving the cost minimization problem:

$$
\min C_{t}=E_{t-1} \sum_{i=0}^{\infty} \beta^{i}\left[b_{0}\left(p_{t+i}-p_{t+i}^{*}\right)^{2}+\sum_{k=1}^{m} b_{k}\left(p_{t+i}-p_{t+i-k}\right)^{2}\right]
$$

where $p_{t}$ denotes the actual price level and $p_{t}^{*}$ its target value. Equation (7) generalizes the adjustment cost assumption to go beyond the level-adjustment cost specification commonly used in standard linear quadratic models-e.g. Sargent (1978) and Rotemberg (1982). For instance, for $m=2$, equation (7) says that it is

\footnotetext{
${ }^{6}$ The details of the modeling approach are described by Tinsley (1993).
} 
costly not just to change the price level, but also its rate of change. ${ }^{7}$ The solution to the above minimization problem leads to the following decision rule for inflation:

$$
\Delta p_{t}=a_{0}+a_{1}\left(p_{t-1}-p_{t-1}^{*}\right)+\sum_{j=1}^{2} \rho_{j} \Delta p_{t-j}+\sum_{j=0}^{\infty} \gamma_{c, j} \Delta c_{t+j}+\sum_{j=0}^{\infty} \gamma_{u, j} u_{t+j}+e_{p, t}
$$

where the cyclicality of the mark-up is captured by the term involving the unemployment rate $\left(u_{t}\right)$, and $e_{p, t}$ is a price shock.

In the context of the model's price setting behavior, equation (8) has a straightforward economic interpretation: It can be thought of as a forward-looking Phillips curve where today's inflation depends not only on past and expected inflationary developments, but also on anticipated conditions in the labor market. ${ }^{8}$ In a broader context, (8) allows for the explicit decomposition of macroeconomic dynamics into "adjustment costs" and expectational factors. In particular, the lagged dependent variable appears on the right-hand-side of (8) solely to reflect the nature of the generalized adjustment costs. Thus, if we only had level-adjustment costs-i.e. producers can adjust the rate at which they change their prices costlessly-then it can be shown that $\rho_{j}=0$ for all $j$. In contrast to this explicit attempt to decompose dynamics between expectations and adjustment costs, traditional specifications of the Phillips curve use lagged values of inflation to capture both "inflation inertia" and the usefulness of past inflation in predicting its future values.

Equations like (8) permeate all aspects of key non-financial sectors of the model. For households, the two-stage decision problem of consumers involves, first, specifying "target" consumption as a function of lifetime income, and, second, solving an optimization problem similar to (7). Again, the result is a decision

\footnotetext{
${ }^{7}$ Thus, though the model does not explicitly specify the structure of the dynamic frictions preventing fully flexible prices, the above specification captures the notion that changing the inflation rate is costly (e.g. Fuhrer and Moore, 1995) .

${ }^{8}$ The estimated coefficients are such that expectations of high unemployment lead to a deceleration in price increases.
} 
rule where consumption growth is a function not only of the gap between actual and target consumption, but also of past values of consumption growth and expected changes in consumption fundamentals. Firms' factor allocation and inventory accumulation decisions are also derived within this framework. ${ }^{9}$

Financial Markets. The main financial equations involve three long-term interest rates-for the 5- and 10-year government bonds and the 30-year corporate bond-and the stock market. Adjustment costs are assumed to be small enough to be negligible so that there is no distinction between target and actual values of financial variables.

Long-term interest rates are determined according to the expectations theory of the term structure. Following Shiller (1979), the yield on a long-term bond of maturity $m$ is given by the expected future path of short-term interest rates $\left(i_{t}\right)$ plus a term premium $\left(\phi_{m, t}\right)$ :

$$
i_{m, t}=\sum_{j=0}^{m-1} \tau_{j} i_{t+j \mid t}+\phi_{m, t}
$$

The model's equation for stock market also follows standard specifications. It is based on the familiar notion that stock prices reflect the present discounted value of expected dividends.

\subsection{Expectation Formation}

As discussed above, expectations play a potentially important role in the evolution of both financial and non-financial variables in FRB/US. The version of the model used for the experiments described in this paper assumes that agents base their expectations on a simplified reduced-form representation of the economy. Thus, rather than explicitly using all 300+ equations and identities that make up

\footnotetext{
${ }^{9}$ Brayton and Tinsley (1996) provide details of individual equations
} 
the model, agents rely on small-scale vector-autoregressions to form their expectations. Such expectations are within the spirit of our disinflation exercise. As stressed by Taylor (1993), fully rational expectations may be unrealistic during the transition period after a new policy has been put in place. Certainly, the assumption that agents may be not fully aware of the policy generating process motivates our analysis of credibility.

The VAR forecasting systems vary from sector to sector-for example, while the price setting decision leads firms to forecast the unemployment rate, households are required to generate explicit income forecasts when deciding how much to consume. Nevertheless, all small-scale forecasting models include a restricted VAR in three core macroeconomic variables: inflation $\left(\pi_{t}\right)$, short-term interest rates $\left(i_{t}\right)$, and an output gap $\left(y_{t}\right) .{ }^{10}$ The subsystem formed by these three variables can be written as:

$$
\begin{aligned}
\Delta i_{t} & =\theta_{1}\left(\pi_{t-1}-\pi_{\infty \mid t-1}^{e}\right)+\theta_{2}\left(i_{t-1}-i_{\infty \mid t-1}^{e}\right)+\theta_{3} y_{t-1}+A_{1}(L) x_{t-1} \\
\Delta \pi_{t} & =\theta_{4}\left(\pi_{t-1}-\pi_{\infty \mid t-1}^{e}\right)+\theta_{5}\left(i_{t-1}-i_{\infty \mid t-1}^{e}\right)+\theta_{6} y_{t-1}+A_{2}(L) x_{t-1} \\
\Delta y_{t} & =\theta_{7}\left(\pi_{t-1}-\pi_{\infty \mid t-1}^{e}\right)+\theta_{8}\left(i_{t-1}-i_{\infty \mid t-1}^{e}\right)+\theta_{9} y_{t-1}+A_{3}(L) x_{t-1}
\end{aligned}
$$

where $A_{i}(L)$ are polynomials in the lag operator $L$, and $x_{t} \equiv\left[\Delta i_{t}, \Delta \pi_{t}, \Delta y_{t}\right]^{\prime}$. $\pi_{\infty \mid t-1}^{e}$ is the private sector's expected long-run inflation rate, and $i_{\infty \mid t-1}^{e}$ is analogously defined (as $\left.r^{*}+\pi_{\infty \mid t-1}^{e}\right) .{ }^{11}$ The estimated coefficients of the core VAR

\footnotetext{
${ }^{10}$ Effectively, the inclusion of these three variables endows all agents in the economy with knowledge of its three essential macroeconomic relationships: a Phillips curve, a monetary policy rule, and an IS curve. We also explored simulations with a core VAR that replaced equation (10) with an expectations version of the policy rule (1) or (2), and we obtained very similar results with such policy-consistent expectations.

${ }^{11}$ When estimating the model, long-run expectations for inflation are taken from survey data, and those for the federal funds rate from the forward interest rates implicit in the term structure of interest rates. In the terminology of Kozicki and Tinsley (1996), these expectational variables represent "moving endpoints" for inflation and interest rate forecasts.
} 
imply that the system "error corrects" so that

$$
\begin{aligned}
\lim _{j \rightarrow \infty} \pi_{t+j \mid t-1}^{e} & =\pi_{\infty \mid t-1}^{e} \\
\lim _{j \rightarrow \infty} i_{t+j \mid t-1}^{e} & =i_{\infty \mid t-1}^{e} \\
\lim _{j \rightarrow \infty} y_{t+j \mid t-1}^{e} & =0
\end{aligned}
$$

Long-run expectation variables play an important role in the behavioral equations described above. Take, for example, the model's modified Phillips curveequation (8): To forecast future values of the unemployment rate, firms rely on an expectational model composed of the 3-equation core VAR system and an additional equation relating the unemployment rate to its own lags, and lagged values of inflation, short-term interest rates and the output gap. Thus, as they look further and further into the future, their unemployment rate forecast becomes increasingly more affected by, say, their long-run inflation rate forecast. More important for the purposes of this paper, long-run inflation expectations play an important role in the workings of a policy to achieve disinflation. For instance, if the policy is fully credible, then $\pi_{\infty \mid t-1}^{e}$ coincides with the long-run inflation target implicit in the disinflation effort. In contrast, if $\pi_{\infty \mid t-1}^{e}$ is persistently above the monetary authority's long-run inflation target, then the private sector underestimates future unemployment rates and overestimates increases in production costs. According to (8), these misperceptions would lead to higher increases in output prices than otherwise and, consequently, a tighter monetary policy stance than in the case of full credibility.

\section{Model Simulation Results}

Our goal is to compare the performances of the opportunistic and deliberate approaches to disinflation. We do this by conducting stochastic simulations of the FRB/US model. All of the simulations start from a steady state baseline with the 
inflation target and actual inflation both at 5 percent. The stochastic simulations begin with the announcement of a 3 percent inflation target. The deliberate policymaker strives for this new target by following the Taylor-type rule in equation (1) with $\pi_{t}^{* *}$ equal to 3 . The opportunistic policymaker employs the strategy described by equations (2) and (3). ${ }^{12}$

The stochastic simulations use a bootstrap procedure based on the errors made by key model equations (about 50 in number) over the 1966-1995 period. We ran 1,000 simulations each under opportunistic and deliberate monetary policy. These simulations were run in pairs (which consist of one with each type of policy) that were each characterized by a different sequence of randomly selected macroeconomic shocks over which the disinflation episode took place (which is the obvious variance reduction technique). For each simulation, we recorded the number of years that were required until the disinflation was complete and the ultimate inflation target was achieved. ${ }^{13}$ We also recorded how much the unemployment rate deviated from its steady-state value during each disinflation episode in order to compute the costs associated with each monetary policy strategy. ${ }^{14}$ While the sacrifice ratio and disinflation duration are common metrics for disinflation, we also consider a more traditional discounted quadratic loss function of the type:

$$
\text { Loss }=\sum_{j=1}^{80} \delta^{j}\left(\left(\pi_{t+j}-\pi_{t+j}^{* *}\right)^{2}+y_{t+j}^{2}\right) .
$$

This loss function sums the (discounted) squared deviations of inflation from its

\footnotetext{
${ }^{12}$ For the policy rule parameters, we use Rudebusch's (1997) estimates for the Greenspan period $-\beta_{1}=0.78$ and $\beta_{2}=0.68$. Our results are robust to variation in these parameters.

${ }^{13}$ The disinflation is considered complete in a quarter when the four-quarter inflation rate is at or below the ultimate target and remains there for the next three quarters.

${ }^{14} \mathrm{We}$ measure the cost of disinflation- the sacrifice ratio-as the cumulative annual deviation of the unemployment rate from the natural rate divided by the two-percentage point decrease in the inflation rate. Therefore, if the disinflation policy started at quarter $t=1$ and took $N$ quarters to reach its goal, we compute the sacrifice ratio as as $(1 / 8) \sum_{1}^{N}\left(U_{\left.d e v_{t}\right)}\right.$ where $U \operatorname{dev}_{t}$ are the unemployment rate deviations from the steady state.
} 
target and output from potential during the first 20 years after the disinflation begins. ${ }^{15}$ Thus, for each stochastic simulation, we generated three pairs of observations: namely, the duration of the disinflation, the sacrifice ratio, and the quadratic loss for each policymaker.

Armed with 1,000 observations on sacrifice ratios, losses, and durations of disinflation for each policymaker, we then proceeded to address the main question asked in this paper: Given the stochastic characteristics of the U.S. economy over the past 3 decades — as measured by the FRB/US model—how well can the opportunistic and deliberate policymakers deliver on their announced inflation targets? To address this question, we compare mean and median values of the statistics. In the comparison of sacrifice ratios and the losses, we also used paired-sample $t$-tests and Wilcoxon tests to gauge the statistical significance of the reported differences between the opportunistic and deliberate policymakers.

Table 1 provides a summary of our results under various assumptions about credibility. The top half of the table considers three cases of exogenous credibility: $\lambda_{t}=0$ (no credibility), $\lambda_{t}=.5$, and $\lambda_{t}=1$ (perfect credibility). Consider the intermediate case first. With $\lambda_{t}=.5$, the mean sacrifice rate faced by the deliberate policymaker is 1.24 ; therefore, the cumulative deviation of the unemployment rate from the steady-state during the two-percentage point disinflation is about 2-1/2 percentage-point-years. ${ }^{16}$ This trade-off is less favorable than the 1.08 ratio faced by the opportunistic policymaker. Furthermore, given the p-value of zero for the associated t-test, these differences are statistically significant. Similar results are obtained with the medians (where the p-values are obtained for a Wilcoxon signed-rank test). Thus, it appears that the opportunistic policymaker, by waiting for the appropriate shocks, is able to reduce inflation with less cumula-

\footnotetext{
${ }^{15}$ The value of delta used is 0.98 , and the output gap is defined as twice the unemployment gap in accord with Okun's Law.

${ }^{16}$ This sacrifice ratio is very close to the one calculated by Ball (1994). Using a simple backof-the-envelope calculation with quarterly U.S. data, he calculates a ratio of about 1.2 percentage points of unemployment per percentage point disinflation.
} 
tive unemployment than the deliberate policymaker. Of course, waiting for shocks increases the duration of the disinflation, which averages (in mean) 5.56 years for the opportunistic policymaker and 3.77 years for the deliberate one. (In all cases, the differences in the duration of the disinflations across the two approaches were very significant, so p-values are not reported for these statistics.) Still, as measured by simple quadratic loss, with equal weights on inflation and output deviations, the opportunistic policymaker does suffer a slightly smaller loss. Again, in all cases the differences across the two approaches were very significant, so p-values are not reported for these statistics. This last conclusion may depend on the relative weights assigned to output and inflation deviations.

Similar qualitative results are obtained for the case of perfect credibility, although both the sacrifice ratios and the disinflation durations are quantitatively smaller. In the case of no credibility, however, the results are less clear in that the sacrifice ratios and losses for the deliberate policymaker actually fall below those of the opportunistic one.

Of course, as argued above, credibility is likely to respond endogenously to the performance of the policymaker, and results with endogenous credibility are given in the lower half of table 1. In particular, as actual or anticipated progress is made toward the inflation target, the credibility of that target is likely to rise. The mechanisms for determining credibility are described in equation (4) and (5). In our simulations, we set $\alpha=.67$, which translates into a three percentage point range of credibility around the target. ${ }^{17}$ Under the backward-looking mechanism depicted in (4) — credibility by outcome - if actual inflation is outside of this range, then the target has no credibility. Credibility is gained incrementally as the target is approached. In this case, as shown in table 1, the deliberate policy maker actually has a lower sacrifice ratio and a smaller quadratic loss than the opportunistic one. This is also the true for the forward-looking specification of credibility (cred-

\footnotetext{
${ }^{17}$ Our results are robust to some variation in $\alpha$.
} 
ibility by behavior) and for the credibility-by-announcement mechanism (where the credibility of the deliberate policymaker is bounded below by .2 after the announcement of the new policy). To shed some light on the movement of endogenous credibility in the three cases considered, the time paths of mean credibility (that is, the average of $\lambda_{t}$ in each quarter across simulations) are shown in figure 1. In all three cases, because the deliberate policymaker makes faster progress toward the goal of low inflation, he enjoys a faster rise in credibility and a lower sacrifice ratio and loss.

\section{Concluding Remarks}

There is a long history of exploring the performance of various policy rules in economic models. Almost all of this research has been conducted in the context of linear models and rules with a fixed expectations mechanism - either rational or adaptive expectations. Such a framework is not well suited for our investigation along two dimensions. First, our opportunistic policy rule is inherently nonlinear. While such a rule is very difficult to motivate with a symmetric loss function and linear constraints, as noted in the introduction, it does appear to hold considerable appeal for some policymakers. Second, our interest is in a period that is clearly transitional-the disinflation-again, mirroring the interests of policymakers. Such a transition will likely involve learning and credibility and changes over time in the expectations formation process.

Given the somewhat atypical, but clearly important, topic of our investigation, there are few clear answers in the literature to the many modeling choices required. What is the nature of learning during a policy transition? How are expectations formed? How will the success of an opportunistic policy be judged? Our results are of course dependent upon the modeling choices that we have made, but still we see them as useful, not for their precise quantitative answers, but for providing a cautionary tale. Namely, there seems to be a fundamental tension be- 
tween credibility and opportunism. The public may well be skeptical about the importance of an ultimate inflation target when it is promulgated but not acted upon by an opportunistic central bank, and this skepticism may lead to a higher cost for a disinflation policy. 


\section{References}

Amano, Robert, Paul Fenton, David Tessier, and Simon van Norden, "The Credibility of Monetary Policy: A Survey of the Literature with some Simple Applications to Canada," 1997. Manuscript, Bank of Canada.

Ball, Laurence, "What determines the sacrifice ratio?," in N.G. Mankiw, ed., Monetary Policy, Chicago: University of Chicago Press, 1994, pp. 155-182.

Bank of Canada, "Press Release: Targets for Reducing Inflation," Bank of Canada Review, March 1991, pp. 5-6.

Blackburn, Keith, and Michael Christensen, "Policy Credibility: Theories and Evidence," Journal of Economic Literature, 1989, pp. 1-45.

Bomfim, Antulio, Robert Tetlow, Peter von zur Muehlen, and John Williams, "Expectations, Learning, and the Costs of Disinflation: Experiments using the FRB/US Model," Bank of International Settlements Conference Papers, 1997.

Brayton, Flint, and Peter Tinsley, eds, "A Guide to FRBUS: A Macroeconomic Model of the United States," 1996. Finance and Economics Discussion Paper 1996-42, Federal Reserve Board.

Brayton, Flint, Eileen Mauskopf, David Reifschneider, Peter Tinsley, and John Williams, "The Role of Expectations in the FRB/US Macroeconomic Model," Federal Reserve Bulletin, April 1997, pp. 227-245.

Croushore, Dean, and Ronald S. Koot, "A Measure of Federal Reserve Credibility," Journal of Policy Modeling, 1994, 16, 215-231.

Fuhrer, Jeffrey, and George Moore, "Inflation Persistence," Quarterly Journal of Economics, 1995, 110, 127-159. 
Fuhrer, Jeffrey, and Mark A. Hooker, "Learning About Monetary Regime Shifts in an Overlapping Wage Contract Model," Journal of Economic Dynamics and Control, 1993, 17, 531-553.

Haldane, Andrew G., ed., Targeting Inflation, Bank of England, 1995.

Huh, Chan G., and Kevin J. Lansing, "Expectations, Credibility, and Disinflation in a Small Macroeconomic Model," 1997. Manuscript, Federal Reserve Bank of San Francisco.

Johnson, David, "On the Credibility of Monetary Policy: International Evidence Based on Surveys of Expected Inflation," 1997a. Manuscript, Wilfrid Laurier University.

_ , "Expected Inflation in Canada 1988-1995: An Evaluation of Bank of Canada Credibility and the Effect of Inflation Targets," 1997b. forthcoming in Canadian Public Policy.

King, Mervyn, "Credibility and Monetary Policy: Theory and Evidence," Bank of England Quarterly Bulletin, February 1995.

Kozicki, Sharon, and Peter Tinsley, "Moving Endpoints and the Internal Consistency of Agents' Ex Ante Forecasts," 1996. Finance and Economics Discussion Paper 1996-47, Federal Reserve Board.

Leiderman, L. and L. Svensson, eds, Inflation Targets, Center for Economic Policy Reserach, 1995.

Meyer, Laurence, "Monetary Policy Objectives and Strategy," Business Economics, January 1997, pp. 17-20.

Orphanides, Athanasios, and David Wilcox, "The Opportunistic Approach to Disinflation," 1996. Finance and Economics Discussion Paper 1996-24. 
Orphanides, Athanasios, David H. Small, Volker Wieland, and David Wilcox, "A Quantitative Exploration of the Opportunistic Approach to Disinflation," 1997. Finance and Economics Discussion Paper 1997-36.

Rogoff, Kenneth, "Reputation, Coordination, and Monetary Policy," in R. Barro, ed., Modern Business Cycle Theory, Harvard University Press, 1989, pp. 236-264.

Rotemberg, Julio, “Sticky Prices in the United States," Journal of Political Economy, 1982, 90, 1187-1211.

Rudebusch, Glenn D., "Is Opportunistic Monetary Policy Credible?," Federal Reserve Bank of San Francisco Economic Letter, October 41996.

__ "Do Measures of Monetary Policy in a VAR Make Sense?," 1997. manuscript, Federal Reserve Bank of San Francisco.

Rudebusch, Glenn D., and Lars E.O. Svensson, "Policy Rules for Inflation Targeting," 1997. manuscript, Federal Reserve Bank of San Francisco.

Sargent, Thomas, "Estimation of Dynamic Labor Demand Schedules Under Rational Expectations," Journal of Political Economy, 1978, 86, 513-542.

Shiller, Robert, "The Volatility of Long-Term Interest Rates and Expectations Models of the Term Structure," Journal of Political Economy, 1979, 87, 1190-1219.

Taylor, John, "Discretion Versus Policy Rules in Practice," in "CarnegieRochester Conference Series on Public Policy,” Vol. 39 1993, pp. 195-214.

Tinsley, Peter A., "Fitting Both Data and Theories: Polynomial Adjustment Costs and Error Correction Decision Rules," 1993. Finance and Economics Discussion Paper 1993-21. 
Table 1

Simulation Results

\begin{tabular}{|c|c|c|c|c|c|c|c|}
\hline \multirow{4}{*}{$\begin{array}{l}\text { Exogenous Credibility } \\
\lambda=0.0\end{array}$} & \multicolumn{3}{|c|}{ Sacrifice Ratio } & \multicolumn{2}{|c|}{$\begin{array}{l}\text { Duration of } \\
\text { Disinflation }\end{array}$} & \multicolumn{2}{|c|}{$\begin{array}{c}\text { Discounted } \\
\text { Loss Function }\end{array}$} \\
\hline & \multirow{2}{*}{ Opp. } & \multirow[t]{2}{*}{ Del. } & \multirow[t]{2}{*}{ p-value } & \multirow[t]{2}{*}{ Opp. } & \multirow[t]{2}{*}{ Del. } & \multirow[t]{2}{*}{ Opp. } & \multirow[t]{2}{*}{ Del. } \\
\hline & & & & & & & \\
\hline & & & & & & & \\
\hline Mean & 2.28 & 2.10 & 0.00 & 10.27 & 6.19 & 295.3 & 267.4 \\
\hline Median & 1.63 & 1.55 & 0.00 & 9.25 & 5.25 & 265.0 & 246.3 \\
\hline \multicolumn{8}{|l|}{$\lambda=0.5$} \\
\hline Mean & 1.06 & 1.23 & 0.00 & 5.58 & 3.77 & 223.2 & 229.9 \\
\hline Median & 0.87 & 0.97 & 0.00 & 5.00 & 3.25 & 211.9 & 217.1 \\
\hline \multicolumn{8}{|l|}{$\lambda=1.0$} \\
\hline Mean & 0.86 & 0.96 & 0.00 & 3.96 & 2.76 & 225.1 & 236.3 \\
\hline Median & 0.72 & 0.77 & 0.00 & 3.50 & 2.25 & 218.8 & 227.8 \\
\hline \multicolumn{8}{|l|}{ Endogenous Credibility } \\
\hline \multicolumn{8}{|l|}{ By Outcome } \\
\hline Mean & 2.06 & 1.88 & 0.00 & 9.43 & 5.52 & 288.3 & 261.4 \\
\hline Median & 1.48 & 1.42 & 0.03 & 8.25 & 4.75 & 258.7 & 240.9 \\
\hline \multicolumn{8}{|l|}{ By Behavior } \\
\hline Mean & 1.70 & 1.54 & 0.00 & 8.21 & 4.51 & 283.2 & 256.3 \\
\hline Median & 1.29 & 1.20 & 0.54 & 7.25 & 3.75 & 252.9 & 237.5 \\
\hline \multicolumn{8}{|l|}{ With Announcement } \\
\hline Mean & 1.70 & 1.32 & 0.00 & 8.21 & 3.97 & 283.2 & 241.0 \\
\hline Median & 1.29 & 1.05 & 0.00 & 7.25 & 3.50 & 252.9 & 226.6 \\
\hline
\end{tabular}

Results under the opportunistic (opp.) and deliberate (del.) policy strategies are given for the sacrifice ratio (in percentage point years of unemployment rate deviations per percentage point of disinflation), the duration of disinflation (in years), and a loss function described in the text. The p-values test the equality of the opportunistic and deliberate means or medians. 
Figure 1: Average Time Path of Credibility

\section{By Outcome}

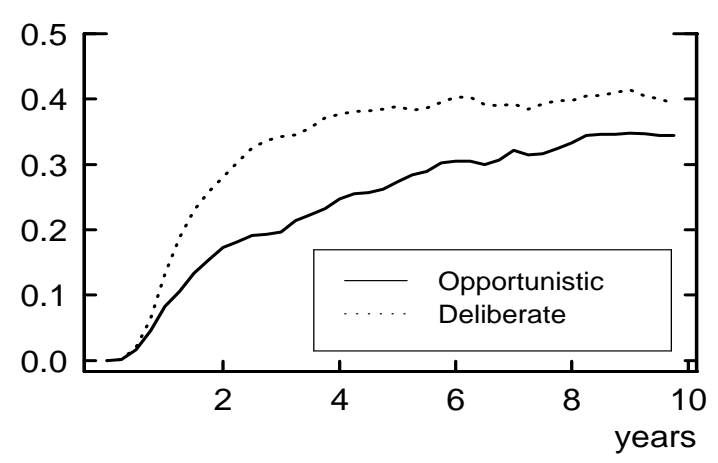

By Behavior

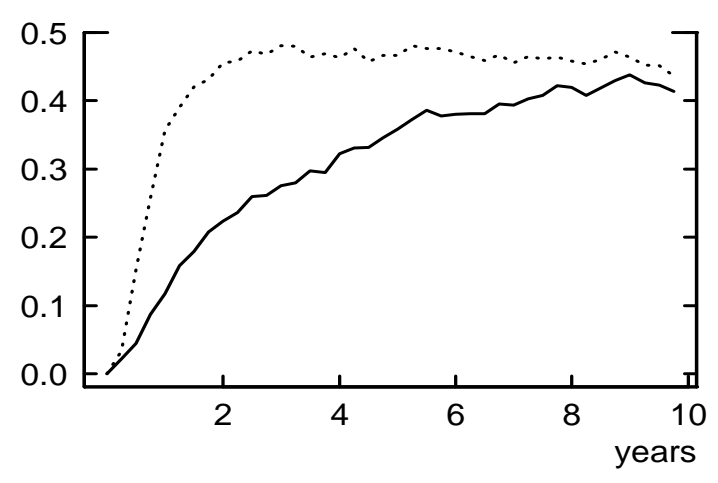

With Announcement

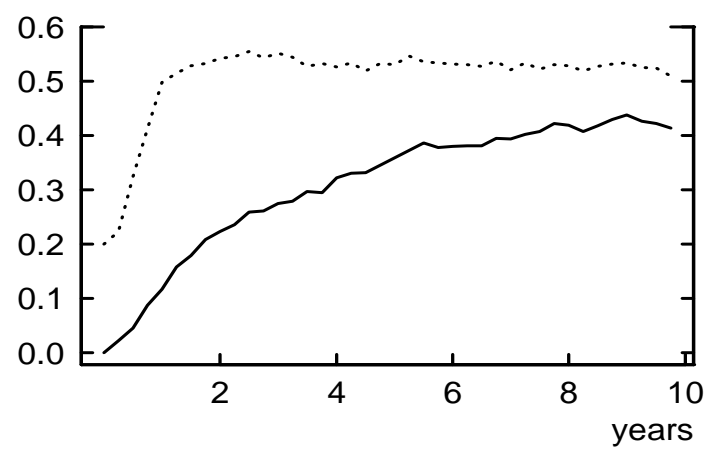

